\title{
Study on Flow Unit of Heavy Oil Bottom Water Reservoir with Over-Limited Thickness in Offshore Oilfield
}

\author{
Wei Wang*, Jie Tan, Songru Mu, Bo Li, Wentong Zhang \\ Bohai Oilfield Research Institute of CNOOC Ltd., Tianjin Branch, Tianjin, China \\ Email: *wangwei16@cnooc.com.cn
}

How to cite this paper: Wang, W., Tan, J., $\mathrm{Mu}$, S.R., Li, B. and Zhang, W.T. (2019) Study on Flow Unit of Heavy Oil Bottom Water Reservoir with Over-Limited Thickness in Offshore Oilfield. Open Journal of Geology, 9, 507-515.

https://doi.org/10.4236/ojg.2019.99033

Received: April 15, 2019

Accepted: September 13, 2019

Published: September 16, 2019

Copyright $\odot 2019$ by author(s) and Scientific Research Publishing Inc. This work is licensed under the Creative Commons Attribution International License (CC BY 4.0).

http://creativecommons.org/licenses/by/4.0/

\begin{abstract}
The upper Ming section of L oilfield is a typical offshore heavy oil bottom-water reservoir with thick fluvial layers. All horizontal wells are developed by natural energy. Due to the few drilling holes and influence by the resolution of seismic data, it is difficult to describe reservoirs with thickness over 20 meters. In this paper, seismic resonance amplitude inversion technology is introduced to restore the real response of thick reservoirs and interbeds by drilling and drilling verification, and the geological bodies with different thickness are displayed by frequency division RGB three primary colors. Flow units of heavy oil reservoirs with bottom water are divided according to the three major factors of interlayer, lithologic internal boundary and water-oil thickness ratio which have the greatest influence on horizontal well development, thick sand bodies are divided into 10 different flow units in three levels, each unit is separated from each other, and the reservoir structure, water-cut characteristics and water-flooding characteristics are different. The reliability of the research is improved by using the dynamic data of horizontal wells and newly drilled passing wells, which provides a basis for tapping the potential of heavy oil reservoirs with bottom water.
\end{abstract}

\section{Keywords}

Over-Limited Thick Layer, Inversion of Tuned Amplitude,

Frequency Division RGB Fusion, Water-Oil Thickness Ratio, Flow Unit

\section{Introduction}

Since Hearn C.L. put forward the concept of flow unit in 1984, [1] [2], many scholars have expanded the concept by studying reservoir characterization and reservoir evaluation. Relevant studies [3] consider that under the condition of 
similar reservoir rock properties and physical properties, the characteristics of reservoir structure, fluid properties and remaining oil distribution are similar, and there is no geological unit with fault and lithology affecting oil-water flow. It is called "flow unit". The study of flow unit is the key to fine reservoir description and the main goal of development and adjustment. The concept of flow unit and the formation and development of its research methods provide an effective means for understanding reservoir heterogeneity. The study of flow units is a further deepening of the study of reservoir configuration, which combines the distribution of reservoir configuration, the division of flow units and the distribution of remaining oil. From the above definition, we can see that this concept can solve the problem of subdivision of thick reservoir and existing small reservoir well according to different scales, which is of great significance for tapping potential and detailed description of oilfield. At present, there are two main methods for dividing flow units at home and abroad: 1) Physical property dividing method. This method chooses drilling parameters such as porosity, permeability, particle size, shale content and so on, and carries out quantitative dividing of flow units between wells by cluster analysis and random simulation, which requires very high sample points. 2) The second method is lithofacies analysis. On the basis of cycle division and correlation, the reservoir sedimentary thickness and lithologic boundary are discussed, which can be divided into four scales: large, medium, small and micro. According to the degree of core research, it can be precise to micro scale. Because the following studies on fluvial oilfields in domestic offshore oilfields are typical high porosity and permeability oilfields with few drilling wells and high core cost, lithofacies analysis method should be adopted mainly according to commonly used seismic data, which is limited by the resolution of seismic data from thick reservoirs. At present, domestic research scale is too large and uncertain. Therefore, starting from the original seismic data, this paper dissects the frequency. Data, frequency division method is used to study the distribution characteristics of this seemingly "sand-filled" reservoir, which is rarely reported at home and abroad.

Offshore oilfields mainly consist of thick-bed heavy oil and bottom water reservoirs of fluvial facies. The reservoir thickness generally exceeds $20 \mathrm{~m}$. Because of multi-stage channel overlapping, it is difficult to precisely split the drilling wells. Many years of production practice has proved that the distribution of residual oil in this pan-connected body is very complex, and it is necessary to carry out flow unit research to improve the development effect. At present, scholars at home and abroad have done a lot of research on the formation mechanism and control factors of flow units from different perspectives. Many research methods have been put forward by analyzing a large number of drilling data. The development cost of offshore oilfields is high and most of them are horizontal wells. Taking $\mathrm{L}$ oilfield as an example, starting from the original earthquake, this paper discusses the flow unit research method of combining frequency division method with bottom water reservoir attributes under the condition of few wells in offshore oilfields. The main contribution of this paper is to break through the 
limitation of large-scale and uncertain original seismic data, to dissect deep frequency data, to study the distribution characteristics of residual oil in water cut rising and passing wells according to the development practice of all horizontal wells in the oilfield, to carry out the study of flow units under the condition of large offshore well spacing, and to open up a new way for tapping potential remaining oilfields or even comprehensive adjustment in the later period. However, due to the different characteristics of the original seismic data in different oilfields, this paper still has further improvement. Later, we can analyze the applicability and differences of this method in different oilfields, and fundamentally put forward suggestions for seismic re-acquisition, but this method can be popularized and applied in ultra-thick layers [4] [5].

\section{The Survey of Oilfield}

The upper Ming member of $\mathrm{L}$ oilfield is a typical meandering river shallow water delta deposit in the sea. The long-term base level decline has resulted in the formation of overlapping foliated thick sand bodies [6]. The average thickness of Um797 sand body reservoir in the main horizon is more than $20 \mathrm{~m}$. During this period, there were obvious transgressive deposits. Early sand bodies developed, showing a "pan-connected body". Later, the range of sand bodies gradually decreased, and the river action was obvious. According to mudstone color of mudstone, it is inferred that shallow water sediment is dominant in the west, delta plain sediment is dominant in the east, and abandoned rivers are developed in some areas (Figure 1). Dual actions of Lake waves and rivers result in overlapping and continuous sand bodies, which change rapidly in transverse direction and develop unevenly in thickness (Figure 2). In the early stage, seven horizontal wells were deployed in the sand body, and the difference was obvious. The water cut of horizontal wells in typical bottom water area exceeded $90 \%$ in three months, but the production of different thickness of bottom water was slightly different; the water cut of horizontal wells in interlayer developed area exceeded $90 \%$ in eight months; while in the Eastern part, the typical edge

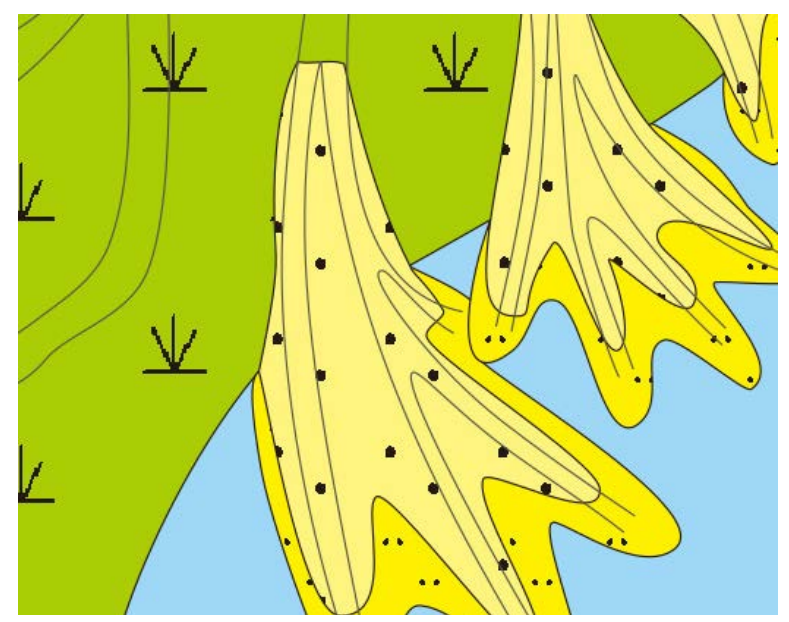

Figure 1. Sedimentary microfacies of Um797 sand layer. 


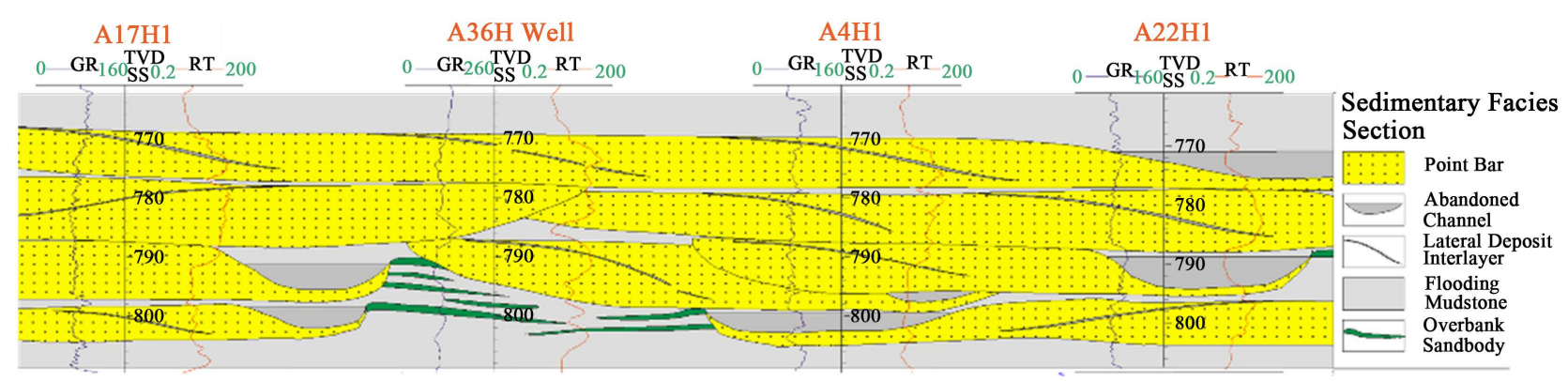

Figure 2. Fine contrast profile of Um797 sand layer.

water area was typical edge water area with strong River action, which was a single channel reservoir, and the water cut of horizontal wells exceeded $90 \%$ in two years. In terms of production characteristics, the main controlling factors of this kind of reservoir production are the development of interlayer and the thickness of water layer. The frequency of seismic data in this area is $0-110 \mathrm{~Hz}$, the main frequency is $55 \mathrm{~Hz}$, and the 90-degree phase-shift data show that the thicker reservoirs have multi-axis artifacts. There are many factors affecting the seismic response using conventional amplitude attributes, and there are uncertainties in the identification of thickness and the internal superimposition relationship [7].

\section{The Method of Research and Expected Results}

Early drilling and drilling proved that the reservoir thickness ranged from 8 to $20 \mathrm{~m}$, in which $60 \%$ of the sand body area exceeded $20 \mathrm{~m}$. In this river channel description, by using the characteristics of seismic frequency bandwidth, through wavelet frequency division, statistical correlation between well point thickness and frequency, three kinds of frequencies of medium/high/low are optimized by fusion algorithm, and the final resonance modulation amplitude is determined by matching and verifying well seismic data. By this method, the real response characteristics of ultra-thick reservoir and interval interbeds are restored to the greatest extent, and through later passing wells. Secondly, the harmonic amplitude data volume is processed to extract three frequency data volumes, and the geological bodies with different background frequencies are displayed by RGB three-color superposition, so as to achieve the purpose of describing the structure and distribution characteristics of thick reservoirs. Secondly, the flow units of bottom-water reservoirs are divided by three factors: interlayer, sedimentary barrier and water-oil thickness ratio, which have the greatest impact on bottom-water reservoirs, and by enriching the verification of flooding data. Although there are few well data, according to the general characteristics of reservoirs, this paper expects to divide the distribution range of reservoirs with thickness of $25 \mathrm{~m}, 15 \mathrm{~m}$ and $8 \mathrm{~m}$. The distribution of internal interbeds can be verified by the water cut rise of horizontal wells. Especially the water flooding data of passing wells in the later stage can greatly reduce this uncertainty, thus ensuring the correctness of flow unit division. Because of the 
strong heterogeneity of reservoirs, the thickness of interbeds is among them. Reservoirs with degrees below $8 \mathrm{~m}$ and above $25 \mathrm{~m}$ are difficult to describe. In the future, the micro-structure of larger scale and smaller scale can be displayed through frequency depth study, so that the inner structure of flow unit can be accurately clarified.

\section{Internal Structure of Thick Sand Layer}

The thickness of Um797 sandstone layer varies in different planes. The average sand body in the west is more than $25 \mathrm{~m}$. Affected by the resolution, there are two or even three sets of axes, some of which are similar to the response of interlayer. A11, A28H and $\mathrm{A} 9 \mathrm{H}$ drilled-through reservoirs show a complete set of thick layers. The 90-degree phase-shift data show the illusion of interlayer. In the actual research process, it is found that the corresponding relationship between different frequencies and thickness is obvious [8]. Under the background of 2100 $\mathrm{m} / \mathrm{s}$ seismic velocity, $25 \mathrm{~m}$ thick reservoirs correspond to $20 \mathrm{~Hz}$ frequency, while $8 \mathrm{~m}$ single channel sand body corresponds to $70 \mathrm{~Hz}$. From these frequency bodies, most of them are selected. The neural network inversion under well matching constraints can obtain a better combination of frequency-division data sets, which are in good agreement with well and seismic data. By using this combination of frequency-division data sets to invert harmonic amplitude, seismic data bodies whose thickness can be characterized by reflection thickness can be obtained in the whole area. This method can be used to characterize the profile of ultra-thick reservoir. Compared with 90-degree phase-shift profile, applying this set of data to the characterization of interlayer in thick sand layer can restore the true response characteristics of interlayer in thick sand layer. Figure 3 is a comparison of the interlayer range depicted by 90 -degree phase-shift data and inversion data of harmonic amplitude modulation. After eliminating the false response, the interlayer [9] which has great influence on development is obviously narrowed. The production performance of horizontal wells can be well verified. Taking $\mathrm{A} 67 \mathrm{H} 1 / \mathrm{A} 72 \mathrm{H}$ and $\mathrm{A} 78 \mathrm{H}$ in areas with low well control degree as examples, the water cut of the three wells breaks through $90 \%$ in less than one month, compared with well control. The $\mathrm{A} 63 \mathrm{H} / \mathrm{A} 68 \mathrm{H}$ region with high degree


Figure 3. Interlayer diagram characterized by 90-degree phase shift (Left) and resonance modulated amplitude inversion profile (Right). 
and interlayer partition is obviously different, and the interlayer range depicted by the inversion method of harmonic amplitude modulation is closer to the real underground situation.

\section{Plane Distribution Characteristics of Thick Sand Layer}

Conventional amplitude attributes are difficult to characterize reservoirs with excessive thickness, and the whole reservoir is full of sand. In practical research, it is found that on the basis of the data processing of the resonant amplitude, the multi-attribute fusion display based on the frequency division RGB color model can distinguish different thicknesses [10]. The specific operation method is to extract attributes of different frequencies from seismic data, and then generate slices of three attributes for RGB mixed-color display. Three-dimensional seismic data volume is transformed into four-dimensional data volume by frequency division and back to three-dimensional data volume by fusion display, but the boundary between different lithologies is highlighted, and the shape of each lithologic combination geological body is distinguished by color, which is the best imaging method of time-frequency analysis at present. This RGB fusion display method has a good effect on highlighting the energy approximation feature area of each frequency division attribute, and can highlight the commonness and weaken the difference. For the recognition of geological bodies, if the energy characteristics are strong in different frequency bands after frequency division, the geological bodies on the color data volume after RGB mode fusion will show obvious differences with surrounding rock in near white characteristics. As shown in Figure 4, using this method, the data are improved obviously. Using RGB attribute fusion attribute slices, the plane contact relationship between geologic bodies with different thickness of Um797 sand body can be clearly seen.

\section{Analysis and Classification of Influencing Factors of Flow Units}

According to the division of flow units, it is considered that the same flow unit has similar seepage characteristics and similar flooding characteristics. Different flow units have different flooding characteristics and distribution characteristics of remaining oil. For thick reservoirs with bottom water, the main factors affecting flow units are sedimentation and development. For Um797 sand body,
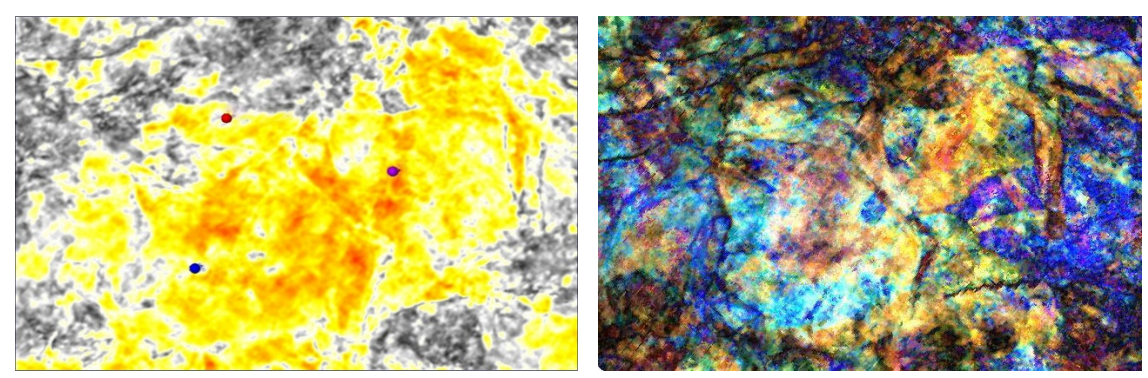

Figure 4. Contrast chart of fusion attribute (Right) between conventional amplitude attribute (Left) and RGB attribute. 
because there are no faults in the oilfield, the development of horizontal wells is affected by reservoir boundary, interlayer and water-oil thickness ratio. Secondly, the development of interlayer plays an obvious disturbing role in the rise of bottom water, and lithologic boundary will store in different structures. Layers are divided into different flow units; for the bottom water area with similar reservoir structure, the thickness of water and oil is different from that of different horizontal wells. Especially in the thin bottom water area, horizontal wells have the dual function of bottom water and edge water drive, while the thick bottom water area is mainly characterized by bottom water ridge, and horizontal wells can reach $90 \%$ in the fastest one month. According to these three factors, sand bodies are divided into 10 flow units. Yuan, abundant flooding data verify the rationality of the division (Figure 5). The overall sand body is divided into three types: the first type is pure oil area, unit 9 is a single channel characteristic, and the water cut of $\mathrm{A} 37 \mathrm{H} 1$ reaches $90 \%$ only after 2 years; unit 6 is close to the thick bottom water area, and many newly drilled crossing wells show water flooding status; unit 7 and 8 are two stages of channel overlapping area because of the existence of interlayer, and the three newly drilled crossing wells are still in the surrounding horizontal wells after many years of production. The second type is thick bottom water area, because of strong bottom water ridge, the radius of the ridge is only $70 \mathrm{~m}$, and only one passing well near the horizontal well shows that the bottom is flooded $1 \mathrm{~m}$. The second type is thick bottom water area, such as Units 3. Because of the development of interbeds, the duration of low water cut period is relatively long. The third type is thin bottom water area, such as Units 1 and 4 . The water cut of horizontal well A78H1 lasts 8 months and reaches $90 \%$. Generally speaking, the flooding situation of newly drilled passing wells confirms the distribution characteristics of remaining oil, which mainly distributes in the top of reservoir and the bottom of interlayer in strong bottom water wells and weak bottom water areas.

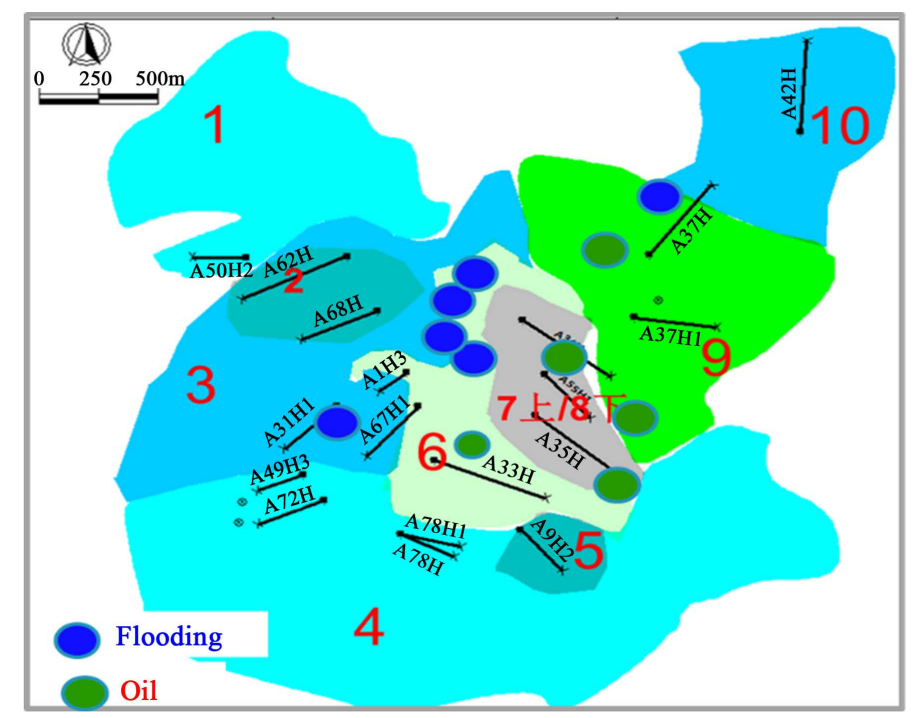

Figure 5. Flow unit diagram of Um797 sand body. 


\section{The Effect of Development Practice}

Five horizontal wells are deployed in the interlayer and thin bottom water area. The average low water cut period lasts for one and a half years when the water avoidance height is obviously reduced. $\mathrm{A} 50 \mathrm{H} 2$ is a newly drilled adjustment well, located in the thin bottom water area, about $160 \mathrm{~m}$ away from the old well, and the water cut is still below $80 \%$ in 5 months when the water avoidance height is only $8.4 \mathrm{~m}$, and the oil production is nearly 100 square/day. That is, the situation of high water cut. Considering that horizontal wells in thin bottom water area have dual functions of water ridge and lateral oil displacement, $\mathrm{A} 33 \mathrm{H}$ well is selected to make the greatest liquid extraction attempt in this offshore oilfield. The effect is obvious. The liquid volume is increased from 1700 to 2700 , the oil production is increased from 45 to 125 square per day, and the water cut is reduced by $1.4 \%$.

\section{Conclusions}

In this paper, the resonance amplitude modulation technique is applied to restore the true response characteristics of thick sand body. On this basis, the frequency division RGB fusion technique is applied to identify reservoir ranges with different thickness. On this basis, the geophysical prospecting method of thick bottom water reservoir-sedimentary genesis-flow unit division method is established by using reservoir boundary, interlayer and water-oil thickness ratio. It is under the condition of high cost drilling in offshore oilfields. Through this research result, adjusting wells can be precisely implemented in thin bottom water or interlayer area, and large-scale fluid extraction can be carried out, which can effectively reduce the development risk. This research result has strong practicability and can be further promoted in similar oilfields.

It should be pointed out that this technique has some limitations, such as that the flow units caused by the smaller 3-level and 4-level interfaces in the thick sand body need to be identified by more drilling and even core data, and the deep excavation frequency data are also needed to realize the smaller-scale flow unit division. With the large-scale adjustment of offshore oilfields in the later stage, more abundant flow units can be obtained. Static data are further excavated.

\section{Conflicts of Interest}

The authors declare no conflicts of interest regarding the publication of this paper.

\section{References}

[1] Hearn, C.L., Ebanks, W.J., Tye, R.S., et al. (1984) Geological Factors Influencing Reservoir Performance of the Hartzog Draw Field, Wyoming. Journal of Petroleum Technology, 36, 1335-1344. https://doi.org/10.2118/12016-PA

[2] Ebanks, W.J. (1987) Flow Unit Concept-Integrated Approach to Reservoir Description for Engineering Projects. AAPG Bulletin, 71, 551-552. 
https://doi.org/10.1306/94887168-1704-11D7-8645000102C1865D

[3] Li, Y. and Liu, J.M. (2005) Principles and Methods of Mobile Unit Research. Geological Publishing House, Beijing, 19-21.

[4] Lan, L.F., Bai, Z.-Q. and Yang, Z.-H. (2010) Classifying Method of Flow Units in Meandering Reviver Sand Bodies. Petroleum Geology and Oilfield Development in Daqing, 29, 59-63.

[5] Liu, C., Zhao, C.M. and Liao, X.W. (2014) A Refined Anatomy of the Internal Structure of Meandering River Reservoirs under Large Well Spacing in Offshore Oilfields and Its Application. China Offshore Oil and Gas, 26, 58-64.

[6] Hu, G.Y., Chen, F., Fan, T.E., et al. (2014) Analysis of Fluvial Facies Compound Sand Body Architecture of the Neogene Minghuazhen Formation of Soil Field in the Bohai Bay. Acta Sedimentologica Sinica, 32, 586-592.

[7] Zhang, X.W., Hu, G.Y. and Fan, T.E. (2018) Seismic Response Analysis and Prediction for Fluvial Reservoir Architecture. China Offshore Oil and Gas, 30, 111-117.

[8] Liu, J.J., Liu, Z. and Qi, Y. (2016) Prediction of Deep-Water Reservoir by Seismic Frequency Division Technology. Acta Petrolei Sinica, 37, 80-87.

[9] Shu, Q.-L. (2006) Interlayer Characterization of Fluvial Reservoir in Guantao Formation of Gudao Oilfield. Acta Petrolei Sinica, 27, 100-103.

[10] Ding, J.C., Jiang, X.D. and Weng, B. (2015) Advantage and Application of High Precision Physical Wavelet Time-Frequency Analysis and Spectrum Imaging Technology Based on Spectrum Decomposition RGB Plotting. China Offshore Oil and Gas, 27, 27-30. 